\title{
Are Women the More Emotional Sex? Evidence From Emotional Experiences in Social Context
}

Article in Cognition and Emotion · July 1998

DOI: $10.1080 / 026999398379565$

CITATIONS

172

4 authors, including:

\section{Lisa Feldman Barrett}

Northeastern University

250 PUBLICATIONS 17,673 CITATIONS

SEE PROFILE

\section{Kristen M. Eyssell}

University of Baltimore

4 PUBLICATIONS 224 CITATIONS

SEE PROFILE
READS

1,087

Some of the authors of this publication are also working on these related projects:

Super aging: Behavioral characteristics and neural substrates of "successful" cognitive-affective aging View project 


\title{
Are Women the "More Emotional" Sex? Evidence From Emotional Experiences in Social Context
}

\author{
Lisa Feldman Barrett \\ Boston College, USA \\ Lucy Robin \\ Indiana University, USA \\ Paula R. Pietromonaco \\ University of Massachusetts at Amherst, USA \\ Kristen M. Eyssell \\ The Pennsylvania State University, USA
}

The present study examined whether sex differences in emotion are related to the social context and addressed differences between global, retrospective, and on-line, momentary self-descriptions of emotional experience and expression. Participants provided global, retrospective descriptions of their emotional characteristics at an initial session, and then provided momentary emotion ratings as well as details about the social context in which they experienced their emotions over a one-week period. We predicted and found that sex-related differences in emotion in global self-descriptions, but not in the averaged momentary ratings of emotion. Furthermore, only sex of the interaction partner elicited sex differences in emotionality; participants experienced and expressed more emotion when in opposite-sex dyads. Although most of the other context variables were themselves associated with emotional experience or expression, suggesting that they were emotionally evocative, none emerged as elicitors of sex differences in emotional experience; felt intimacy in the interaction was associated with sex differences in ratings of emotional expression. Together, the findings present certain caveats to the widely held belief that women are the "more emotional" sex.

Requests for reprints should be sent to Lisa Feldman Barrett at the Department of Psychology, 427 McGuinn Hall, Boston College, Chestnut Hill, MA, 02167, USA; e-mail: BARRETLI@BC.EDU.

The authors thank Agneta Fischer for her very helpful comments on earlier drafts of this manuscript. 


\section{INTRODUCTION}

Many lay people and psychologists alike believe that women are more emotional than are men: Women are believed to experience and express most emotions more intensely and more frequently than are men; men, if they are emotional at all, are believed to experience and express more anger. These beliefs pervade American culture, from self-help books to talk shows, from films to comedy routines. Research confirms that these stereotypes are widely held. Even preschool children hold stereotypic beliefs about sex differences in emotional experience and expression (e.g. Birnbaum \& Croll, 1984; Birnbaum, Nosanchuk, \& Croll, 1980), and these beliefs continue into adulthood (e.g. Grossman \& Wood, 1993; Hochschild, 1983; Lutz, 1990; Shields, 1987).

\section{Self-descriptions vs. Momentary Ratings}

When emotionality is defined as a global disposition which is stable over time and largely independent of social context, women consistently describe themselves as more emotional than do men, citing more intense and more frequent emotional experiences (e.g. Allen \& Haccoun, 1976; Diener, Sandvik, \& Larsen, 1985; Dosser, Balswick, \& Halverson, 1983; Fujita, Diener, \& Sandvik, 1991; Grossman \& Wood, 1993; Kring, Smith, \& Neale, 1994; Snell, Miller, Belk, Garcia-Falconi, \& Hernandez-Sanchez, 1989; Sprecher \& Sedikides, 1993). To describe themselves, people must remember, summarise, and integrate their past experiences into a consistent set of global responses to the questionnaire items, but recalling such information is a reconstructive process. Social cognitive researchers have demonstrated repeatedly that heuristics, cognitive structures, implicit theories, and motivations can lead to inaccurate recollections (for reviews see Fiske \& Taylor, 1991; Greenwald \& Banaji, 1995; Nisbett \& Ross, 1980; Ross, 1989; Schwarz \& Sudman, 1994). Furthermore, participants may be influenced selectively by more salient or theory-consistent experiences when they create an "average" perception on the basis of many different experiences (Stone \& Shiffman, 1994). Therefore, global, retrospective ratings of one's emotional characteristics might be influenced by culturally held beliefs about the link between gender and emotional experience.

Several researchers have suggested that global, retrospective selfdescriptions may reflect sociocultural beliefs about gender differences in emotional experience and expression. In a review, LaFrance and Banaji

\footnotetext{
${ }^{1}$ We use the term "sex difference", rather than "gender difference", because we are not referring specifically to differences in gender role orientation.
} 
(1992) focused on the breadth of self-descriptions, concluding that sex differences in emotion appear primarily when people must make summary judgements of their global emotionality rather than judgements about particular emotional states. Shields (1991) focused on the retrospective nature of some self-descriptions, suggesting that sex differences appear when people are asked to remember previous emotional experiences because such reports are heavily influenced by underlying beliefs about gender and emotion. When recalling their experiences, women might think "I am a woman, and women are emotional, therefore I must be emotional", whereas men might think "I am a man, and men are not emotional, therefore I must not be emotional". In contrast, sex differences are likely to disappear when ratings are made during or immediately after the emotional experience because the immediate environmental cues are more salient and therefore more likely to determine emotional responses.

Preliminary evidence has demonstrated that sex differences in emotional experience are bounded by both the scope of the questions asked and the degree to which respondents must rely on memory when reporting their experiences (Feldman Barrett \& Morganstein, 1996). In two studies, female participants used global, retrospective ratings to describe themselves as experiencing and expressing more emotion than did the male participants, but sex differences did not appear in the momentary reports of emotional experiences that these same participants made across a 2 to 3 month time-span. The momentary ratings may have failed to show sex differences, however, because they were not necessarily made during social interactions; sex differences in emotional experience and expression are more likely to occur in interpersonal, rather than impersonal, settings (LaFrance \& Banaji, 1992). The first goal of the present study was to test the hypothesis that stereotypic sex differences appear in global, retrospective self-descriptions of emotional characteristics, but not in momentary ratings of emotional experience and expression during social interactions.

\section{The Importance of Social Context}

Reviews of this literature draw different conclusions regarding the status of sex differences in emotional experience and expression. One conclusion is that women experience selected emotions more intensely and more often than do men (e.g. Brody \& Hall, 1993; Fabes \& Martin, 1991; Fischer, 1993). Another is that sex differences are stronger for the expression of emotion than for emotional experience because men's and women's different social roles lead them to follow different display rules (e.g. Brody \& Hall, 1993; Shields, 1991). Finally, some social scientists propose a 
gender-in-context approach (e.g. Deaux \& Major, 1987; Shields, 1991), arguing that aspects of social situations interact with gender to enhance or attenuate observable sex-related differences.

The second goal of the present study was to distinguish between emotional experiences and emotional expression and to place them in their social contexts. We focused on: (1) characteristics of the interaction partner; and (2) characteristics of the interaction itself as the contexts that might be especially likely to interact with sex in influencing emotional experience and expression.

\section{Characteristics of the Interaction Partner}

Previous research using global, retrospective questionnaire methods has indicated that the sex of an interaction partner is an important contextual factor for sex differences in emotional disclosures, but the direction of the effect is far from clear. One study (Snell, Miller, \& Belk, 1988) found that women were willing to disclose their emotions with both men and women, whereas men were more willing to disclose only to women. In contrast, another study (Snell et al., 1989) indicated that women were more willing to discuss emotions with other women. Other work (Allen \& Haccoun, 1976) found, however, that both sexes reported expressing more emotion in opposite-sex interactions, but that this effect was more consistent for women than for men. Based on this research, we hypothesised that sex of interaction partner would be a contextual variable that differentially affects how men and women express their emotions, although the precise nature of the effect remains to be determined.

Closeness of the interaction partner is a second contextual variable that differentially affects how men and women express their emotions. Although women tend to disclose more than do men, this difference is particularly salient when interacting with strangers (Dindia \& Allen, 1992). Women are much more likely to disclose information to a stranger than are men, who tend to reserve their disclosures for close others. Thus, a gender in-context perspective would predict that sex differences in emotional expression should be most evident in interactions with strangers and less evident in interactions with close others. Whereas women might feel free to express emotion with a wide variety of interaction partners, men might reserve emotional disclosures for particularly close partners.

We also explored the potential impact of interaction partner characteristics on differences in emotional experience. No specific predictions were made, however, because to our knowledge these relationships have not been previously addressed in the literature. 


\section{Characteristics of the Interaction}

We examined whether sex-related emotion differences would vary as a function of characteristics of the interaction. Popular culture and scientific inquiry alike attribute intimacy and communal motives to women, but power, control, and agency motives to men. Because intimacy and social control are thought to be differentially associated with gender, they may evoke different patterns of emotional response for men versus women (Brody \& Hall, 1993).

Miller's (1984) relational theory holds that women's experience of the self is organised around being able to establish and maintain affiliative relationships, primarily because they are powerless in society. In the course of socialisation, women are thought to learn to connect to others, to maintain those connections as a source of self-worth, and to define themselves in terms of their relationships (Joseph, Markus, \& Tafarodi, 1992; Markus \& Oyserman, 1989). Women describe their friendships as more intimate than do men (Sherrod, 1989), and their manner of communication is more intimacy-promoting than is men's (Dindia \& Allen, 1992; Snell et al., 1988, 1989). Women also report more of an interpersonal basis for their emotional responses (Allen \& Haccoun, 1976). Much of this research linking women with intimacy and affiliation motives is based on global, retrospective self-report, and thus may suffer from the same weakness as self-descriptions of emotion characteristics; that is, these self-report ratings might be influenced by culturally held, gendered beliefs about relationships. If we formulate a hypothesis based on these findings, however, then we would predict that sex differences in emotional experience or expression should be enhanced during intimate interactions. ${ }^{2}$

Issues of power and control are thought to be more relevant for men than for women. According to such theorists as Chodorow (1978) and Miller (1984), men learn to define themselves in terms of their separateness and their status in the social system. According to this line of thinking, dominance is more central to men's self-concept than it is to women's (Josephs et al., 1992). Indeed, same-sex male dyads more frequently engage in behaviour to maintain dominance and position in the social hierarchy than do other types of dyads (Maccoby, 1990). This research, too, might reflect sex stereotypes, because much of the evidence is based on self-report data. Nonetheless, the hypothesis derived from these findings would be that interactions which involve very little (or very much) personal control may enhance sex-related differences in emotional experience or expression.

${ }^{2}$ The degree of intimacy experienced in a social interaction can be separated from the closeness of the partner, in that participants might have feelings of intimacy in interactions with partners whom they have not known long enough or do not know well enough to consider those partners close. Thus, predictions for the two types of contexts vary from one another. 


\section{THE PRESENT STUDY}

In the present study, male and female participants initially described their emotional characteristics by completing a series of individual difference questionnaires. Participants also provided detailed quantitative descriptions of their social experiences, their interaction partners, and their emotional reactions immediately after every social interaction for a one-week period using a variant of the Rochester Interaction Record (RIR; Reis \& Wheeler, 1991). We predicted that sex differences would appear in global, retrospective self-descriptions of emotion characteristics, but not in momentary reports of emotion. Next, we explored whether aspects of social situations interacted with gender to enhance or attenuate observable sex differences in emotional experience and expression. We predicted that the characteristics of the interaction partner would provide a context for the appearance of sex differences in emotional expression. The sex of an interaction partner should produce sex differences, such that either men would express more emotion to women partners, or both sexes would report expressing more emotion in opposite-sex interactions. The closeness of an interaction partner should produce sex differences, such that men and women would look most different in their emotional expressions when interacting with strangers. In addition, we explored the relationships between the characteristics of the interaction partner and sex differences in momentary emotional experience, although we had no formal predictions per se. Finally, we explored whether aspects of the interaction itself provided a context for the appearance of self-related differences in emotion. If intimacy and communal motives are linked to women's roles, whereas power and control motives are linked to men's roles, then intimate social interactions or interactions where personal control is constrained or enhanced might produce sex differences in emotional experience or expression.

\section{METHOD}

\section{Participants}

The sample consisted of 70 participants (28 male, 42 female) who had complete data for the interaction record ratings. ${ }^{3}$ Missing data exist because some participants left some items blank on the personality

${ }^{3}$ The study began with 104 participants who were selected from a larger undergraduate subject pool, 56 sampled from the University of Massachusetts and 48 sampled from the Pennsylvania State University. The sample was originally designed to study the social interaction patterns associated with adult attachment styles (see Pietromonaco \& Feldman 
questionnaires. All 70 participants completed the positive emotion and compliance facet scales of the Revised NEO Personality Inventory (NEO PI-R; Costa \& McCrae, 1992); 68 of these participants fully completed the affect intensity measure (AIM; Larsen \& Diener, 1987), and the anxiety, hostility, depression, warmth, and feeling facet scales of the NEO PI-R. Sixty-six participants had complete data for all relevant personality measures. All participants received course credit and tickets for a $\$ 50$ lottery for their participation.

\section{Self-description Measures}

Although participants completed a battery of individual difference measures before the experience-sampling portion of the study began, only those tapping assessments of emotional experience and expression, or sex role stereotypes, are relevant to this report. Affect intensity was assessed using the affect intensity measure (AIM; Larsen \& Diener, 1987). Examples of items from the AIM (alpha $=0.92 ; 40$ items) include "When something good happens, I am much more jubilant than others" and "When I solve a small personal problem, I feel euphoric". Intensity of emotional experience and receptivity to one's inner feelings and emotions were assessed using the openness facet from the Revised NEO Personality Inventory (NEO $P I-R$; Costa \& McCraw, 1992) openness to experience scale. Examples of items from the feelings facet (alpha $=0.82 ; 8$ items) include "I rarely experience strong emotions" (reversed) and "I experience a wide range of emotions or feeling". Components of negative affect were assessed using three facets of the NEO PI-R neuroticism scale. Examples of items from the anxiety facet (alpha $=0.84 ; 8$ items) include "I often feel tense and jittery"; from the depression facet (alpha $=0.75 ; 8$ items) include "I seldom feel sad or depressed" (reversed); and, from the hostility facet

Barrett, 1997), and include approximately equal numbers of individuals from each of four attachment styles (i.e. secure, preoccupied, fearful-avoidant, and dismissing-avoidant; Bartholomew \& Horowitz, 1991). Fourteen per cent of the sample (15 participants) did not complete the study. These participants did not differ from those who remained in the study on any of the 5-factor personality factors except for agreeableness. The participants who dropped out of the study described themselves as less agreeable $(M=107.1)$ than did those participants who remained in the study $(M=125.1), t(96)=2.9, P<.01$. In particular, they rated themselves as less compliant $(M=11.1)$ than did the participants who remained $(M=15.4), t(96)=2.7, P<.01$. Twenty-one per cent of the remaining sample (19 participants) reported using their memory to complete more than $25 \%$ of the interaction records. We removed these participants from the analysis to minimise the influence of recall bias on participants' reports. Subjects who reported using memory to complete their interaction records differed somewhat from the rest of the sample; they evidenced greater neuroticism $(M=115.2)$ than those who did not use memory $(M=96.7), t(87)=2.7$, $P<.01$, and less conscientiousness $(M=107.0$ vs. $M=121.2), t(78)=2.5, P<.01)$. 
(alpha $=0.89 ; 8$ items) include "I often get angry at the way people treat me". The anxiety facet, depression facet, and hostility facet were considered self-descriptions of experiences with fear, sadness, and hostility, respectively. Positive affect was assessed using the positive emotions facet of the NEO-PI R extraversion scale. Examples of items from the positive emotions facet (alpha $=0.89 ; 8$ items) include "Sometimes I bubble with happiness".

Two components of gender role stereotypes related to power and intimacy were assessed using additional facets of the NEO-PI R. The compliance facet of the agreeableness scale (alpha $=0.72 ; 8$ items) measures characteristic reactions to interpersonal conflict (ranging from deference to others to a preference to compete rather than to co-operate) and includes items such as "I would rather cooperate with others than compete with them" (reversed). The warmth facet of the extraversion scale (alpha $=0.83 ; 8$ items) measures interpersonal intimacy and includes items such as "I'm known as a warm and friendly person".

\section{Interaction Record}

We adapted the Rochester Interaction Record (RIR; Reis \& Wheeler, 1991) to assess the quality of participants' interactions, the sex and closeness of their interaction partner, and their emotional reactions to the interactions. The Interaction Record is a fixed-format diary procedure that participants complete after every interaction lasting 10 minutes or longer (Reis \& Wheeler, 1991). We defined an interaction as any encounter with another person or persons in which the participants attended to one another and possibly adjusted their behaviour in response to one another (Reis \& Wheeler, 1991). We called the interactions "social" because they involved at least another person, but the interactions included more than just situations in which the participants socialised for entertainment purposes (e.g. we sampled interactions at work, over the telephone, during classes, on errands, etc.).

For each interaction, participants provided information such as the number of partners, the initials of partners for each interaction, and who initiated the interaction. Next, they indicated the sex of their interaction partner (male, female) or partners (male, female, or mixed). Participants then rated several aspects of the interaction on a 5-point Likert scale $(1=$ not at all, $3=$ moderately, $5=$ very much): They rated the quality of the interaction, including the degree of intimacy and own-versus othercontrol over the interaction. They also rated a range of emotion adjectives to indicate their emotional reactions to the interaction, including happy, sad, nervous, surprised, angry, embarrassed, and ashamed. Participants also rated the intensity of their experience ( 1 item) and how much they 
expressed their emotions in the interaction (1 item). At the conclusion of the study, they also rated their degree of closeness to their main interaction partners using a 7-point Likert scale.

\section{Procedure}

Participants attended three laboratory sessions. During the first session, the experimenter explained that the study concerned how people think and feel about their social interactions with others, and that participants would keep records of all of their social interactions for 7 days. To encourage participation, the experimenter also explained that participants would receive extra credit plus tickets for a $\$ 50$ lottery to be held at the end of the semester. To preserve confidentiality, participants selected a code name to write on all of their study materials. Participants also completed several questionnaires during the first session (for a complete description see Pietromonaco \& Feldman Barrett, 1997). Afterwards, the experimenter explained the event-contingent procedure for completing the interaction records, and carefully defined all items on the interaction record form. For example, the experimenter indicated that "intimacy" referred to the extent to which the participants felt interpersonally close to their interaction partners in a given interaction and did not necessarily refer to sexual activity. The experimenter emphasised the importance of answering honestly when using the interaction records and of completing a record as soon as possible (within 15 minutes) after each interaction. In addition to oral instructions, participants received written instructions to which they could refer during the course of the study. Participants took home some practice interaction records, along with another set of self-report measures.

During the second laboratory session, participants returned their completed questionnaires, and reviewed their practice interaction records with the experimenter. The experimenter answered all questions and gave participants a final written set of instructions for completing 7 days of interaction records. Participants returned their interaction records three times during their recording week, and they received extra lottery tickets for returning their forms on time. The experimenter phoned, within 24 hours, any participants who did not return their forms on time and reminded them to return the forms.

During the third laboratory session, the experimenter interviewed participants about their reactions to the study. To ensure that participants followed all instructions, the experimenter asked several specific questions about the accuracy with which participants had recorded their interactions, including: (a) whether they had recorded all of their interactions and, if they had not, what percentage they did not record (percent not recorded $M=$ $15.4 \%, \mathrm{SD}=14.8)$; and (b) whether they had completed any interaction 
records from memory and, if they had, the percentage of interaction forms that they had completed from memory. The experimenter stressed that participants would not be penalised in any way (i.e. they would still receive credit and lottery tickets) if they had not followed instructions, and that we were simply interested in obtaining an accurate picture of their data. Overall, the majority of participants $(81 \%$ of the final sample) reported that they documented at least three-quarters of their social interactions over the observation week.

Sixty-nine percent of the interactions $(N=1559)$ from the total data set were used for the present report because we selected only those involving the participant and one other interaction partner (either male or female). We analysed only dyadic interactions to minimise the other influences on emotional experience and expression that might be present in larger social groups. ${ }^{4}$

\section{RESULTS}

\section{Overview of Data Analyses}

The interaction data in this study conformed to a multilevel data structure (Kenny, Kashy, \& Bolger, 1998), including both lower-level and upperlevel data. The lower-level data consisted of multiple data points for each individual across time. Participants indicated the characteristics of their social interactions and their interaction partners, and rated their emotional experience and expression, all of which were measured on an interactionby-interaction basis across many interactions. These lower-level data were nested within upper-level units, or participants, and participants could be grouped by whether they were male or female. We used hierarchical linear modelling (Bryk \& Raudenbush, 1987, 1992; Bryk, Raudenbush, Seltzer, $\&$ Congdon, 1989) to analyse the interaction data because it allowed us to analyse within-subject (lower-level) and between-subject (upper-level) variation simultaneously, thus allowing us to model each source variation while taking the statistical characteristics of the other level into account. The global, retrospective self-descriptions of emotional experience and expression consisted of upper-level data only, and thus were analysed using ordinary least-squares estimation procedures.

4 Analyses of the total data set have been published in two previous reports. The first focused on the relationship between adult attachment and interpersonal experiences (Pietromonaco \& Feldman Barrett, 1997). The second report focused on the accuracy of the 5factor model of personality (Feldman Barrett \& Pietromonaco, 1997). The hypotheses tested and analyses reported in those reports do not overlap with those presented here. 
To avoid the possibility of Type II errors in the context of theoretically derived predictions, we established an alpha of 0.05 , two-tailed for analyses of the momentary emotion ratings; we used an alpha level of 0.01 when evaluating effects that we did not predict. To avoid the possibility of Type I errors given the number of analyses performed on the momentary emotion ratings, we do not describe any of these effects that did not reach an alpha of 0.05; all findings are described for the self-description data. All predictors were centred for all of the regression analyses (Aiken \& West, 1991).

\section{Self-descriptions vs. Momentary Emotion Ratings}

We first performed a MANOVA on the battery of individual difference measures including participants' sex as the grouping variable. The MANOVA was statistically significant $F(9,56)=5.32, P<.001$. Univariate ANOVAs indicated that women described themselves as more emotional than did men. Means and standard deviations are presented in Table 1. Women described themselves as more affectively intense, more open to their feelings, more anxious, more sad, and more pleasant than men. Consistent with gender role stereotypes, women described themselves as warmer and marginally more compliant than did men.

We next considered whether there were sex differences in emotional experience and expression across all the dyadic social interactions that were recorded by participants during the event-contingent sampling portion of the study. One hierarchical linear model was used to estimate sex differences for each emotion rating (i.e. happy, sad, nervous, surprised, angry, embarrassed, and ashamed, plus intensity and expression). The

TABLE 1

Sex Differences in Global, Retrospective Self-descriptions

\begin{tabular}{|c|c|c|c|c|c|c|}
\hline & \multicolumn{2}{|c|}{ Women } & \multicolumn{2}{|c|}{ Men } & \multirow[b]{2}{*}{$F$} & \multirow[b]{2}{*}{$P$} \\
\hline & $M$ & $S D$ & $M$ & $S D$ & & \\
\hline Affect Intensity & 3.98 & 0.50 & 3.42 & 0.47 & 14.47 & 0.001 \\
\hline Openness to Feelings & 26.38 & 4.27 & 21.14 & 4.53 & 35.58 & 0.001 \\
\hline Anxiety & 17.48 & 6.78 & 13.71 & 3.89 & 7.69 & 0.01 \\
\hline Sadness & 19.63 & 7.05 & 16.25 & 5.63 & 6.40 & 0.01 \\
\hline Hostility & 16.85 & 5.44 & 15.36 & 4.32 & 3.13 & 0.10 \\
\hline Positive Emotion & 22.56 & 5.65 & 17.71 & 4.97 & 13.03 & 0.001 \\
\hline Warmth & 28.63 & 5.19 & 25.57 & 3.73 & 6.25 & 0.05 \\
\hline Compliance & 16.31 & 4.74 & 14.14 & 4.03 & 4.46 & 0.06 \\
\hline
\end{tabular}

Note: $N=66 ;$ degrees of freedom $=1,64$. 
within-subject level of the model estimated the emotion ratings for each individual using the formula:

$$
E_{i j}=b_{0 j}+r_{i j}
$$

where $E_{i j}$ is participant $j$ 's emotion rating on the ith occasion, $b_{0 j}$ is participant $j$ 's average emotion rating across all dyadic social interactions, and $r_{i j}$ is a within-subjects residual component. The between-subject level of the model allowed us to assess whether the sex of the participant accounted for any of the variance in participants' average emotion rating (represented by the estimated regression parameter, $\mathrm{b}_{0 \mathrm{j}}$ ), as follows:

$$
\mathrm{b}_{0 \mathrm{j}}=\mathrm{b}_{00}+\mathrm{b}_{01} *(\operatorname{sex})+\mathrm{u}_{0 \mathrm{j}}
$$

where $b_{00}$ is the mean emotion rating for all participants, $b_{01}$ is the degree to which participants' sex moderates the size of that coefficient, and $\mathrm{u}_{0 \mathrm{j}}$ represents the random variation in average emotion rating (variation that is not accounted for by sex of participant). An effect code ( -1 for men, 1 for women) was used to signify participants' sex.

The results, presented in the first two data columns of Table 2, indicate that on average, men and women did not differ in their momentary reports of specific emotional experiences. Men and women reported equal amounts of happiness, sadness, nervousness, surprise, and anger. Sex differences did appear in the momentary global ratings, however. On average, women rated their momentary emotional experiences as more intense than did men, and they also reported that they expressed their emotions more so than did men.

Thus, as predicted, men and women described themselves in line with gender stereotypes when making global, retrospective self-descriptions: Women described themselves as more affectively intense, more open and sensitive to their feelings, more anxious, more sad, and more happy, than did men; women also described themselves as warmer and more compliant than did men. In contrast, men and women did not differ in their ratings of specific emotional experiences when measured immediately after dyadic social interactions. Consistent with the self-descriptions, however, women rated their momentary emotional experiences as more intense, and also reported that they expressed their emotions more than did men.

\section{Importance of the Social Context: Attributes of the Interaction Partner}

Sex of Interaction Partner. We next considered whether men's and women's emotional responses to their social interactions differed depending on the sex of their interaction partner. As before, we used one 
hierarchical linear model to analyse each type of emotion rating; both participant and partner sex were effect coded. The within-subject level of the hierarchical regression models estimated each participant's emotion ratings, as follows:

$$
E_{i j}=b_{0 j}+b_{1 j} S_{i j}+r_{i j}
$$

where $E_{i j}$ is participant $j$ 's emotion ratings on the ith occasion, $b_{0 j}$ is the average emotion for participant $\mathrm{j}, \mathrm{b}_{1 \mathrm{j}}$ is the degree to which participant $\mathrm{j}$ responds differentially to male versus female interaction partners, $S_{\mathrm{ij}}$ is the sex of the partner for the ith interaction, and $r_{i j}$ is a within-subjects residual component. The between-subject level of the model allowed us to assess whether participants' sex influenced: (1) their mean emotion ratings $\left(b_{0}\right)$; and (2) their emotional response to their interaction partner $\left(b_{1}\right)$, by estimating the degree to which sex of participant accounted for the observed variance in the within-subjects coefficients for participants, as follows:

$$
\begin{aligned}
& b_{0 j}=b_{00}+b_{01} *(\operatorname{sex})+u_{0 j} \\
& b_{1 j}=b_{10}+b_{11} *(\operatorname{sex})+u_{1 j}
\end{aligned}
$$

where $b_{00}$ is the mean emotion rating for all participants and $b_{10}$ indicates whether the average participant responds differently to male versus female interaction partners. The $b_{01}$ and the $b_{11}$ terms represent the degree to which sex of participant moderates the size of those coefficients: The $b_{01}$ term indicates whether there is a sex difference in the average emotion ratings, and the $b_{11}$ term indicates whether participants' sex influences how they respond when interacting with a male versus a female partner. ${ }^{5}$

In these analyses, we will focus primarily on the $b_{11}$ terms (which represents whether response to the interaction partner variable is influenced by a participant's sex) and on the $b_{10}$ terms (which represents the average participant's response to the interaction partner variable). We will not report $b_{01}$ terms (which represents whether there are sex differences in participants' ratings after controlling for the partner variable) unless they differ from the main effects for participants' sex reported above.

${ }^{5}$ In regression equations with interaction terms in which the predictor variables have been centred, the lower-order regression coefficients are not main effects, but instead represent the effect of the predictor on the criterion at the mean of the other predictor variable. In the regression analysis presented, both sex of participant and sex of partner have been effect coded to centre effectively the variables. The effect of participants' sex can be interpreted as the effect of sex on emotion ratings when interacting with an average interaction partner (i.e. the average of male and female). This is not quite equivalent to testing for a main effect of participant's sex as was presented in Table 2 . 


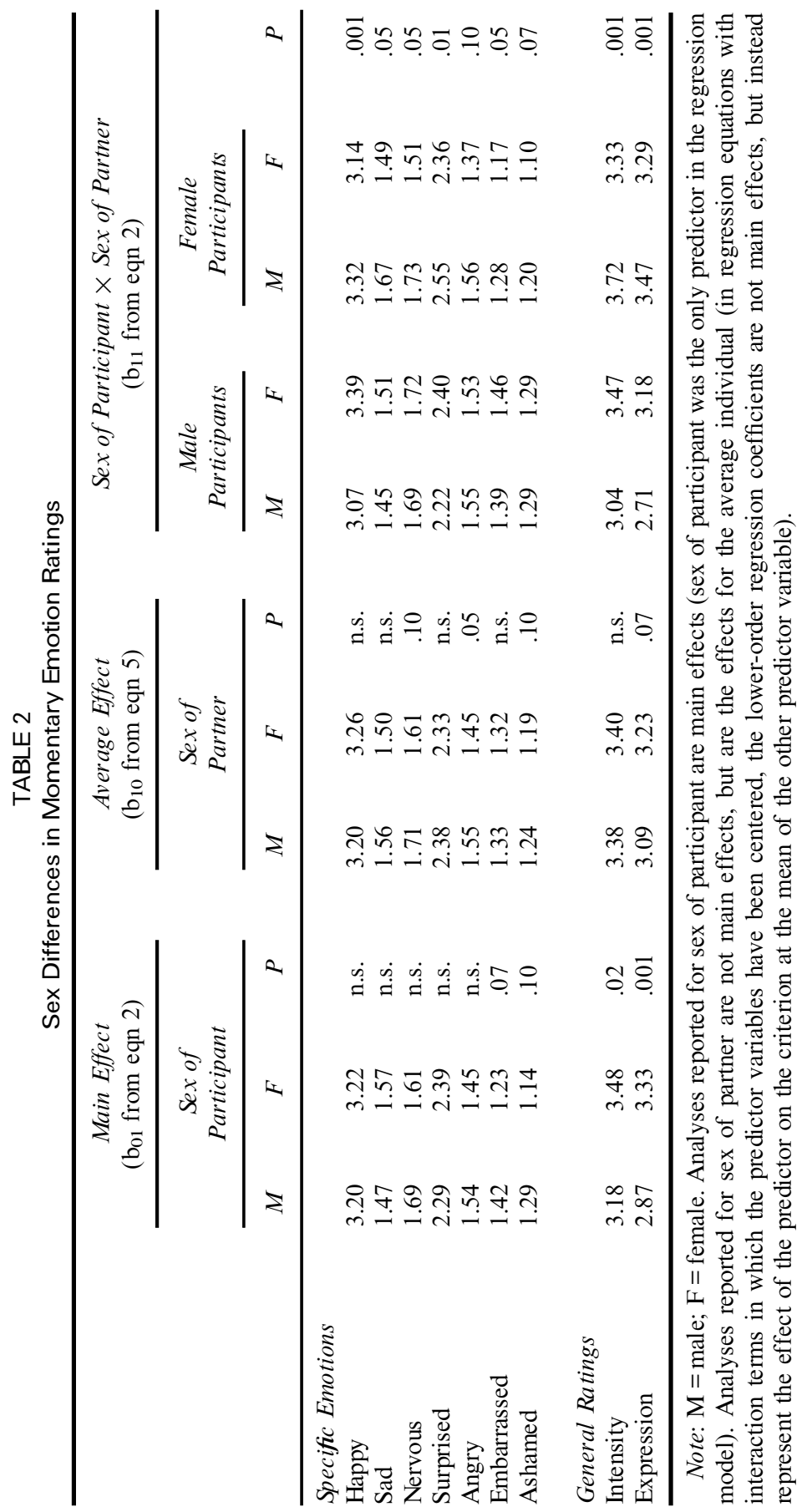


The third and fourth data columns present the average emotional responses when interacting with a male or female partner (the $b_{10}$ terms). When interacting with a man, rather than a woman, participants displayed a trend to report more anger $\left(b_{10}=-.06, t=2.10, P<.05\right)$. There were no other emotion differences in response to sex of interaction partner. The final four data columns in Table 2 indicate that sex differences in emotion ratings were consistently moderated by the sex of the interaction partner (the $b_{11}$ terms). As predicted, the sex of partner interacted with participants' sex to enhance sex differences in ratings of emotional expression, $\left(b_{10 / 1}=-.16, t=3.92, P<.001\right)$; participants reported that they experienced more intense emotion and expressed more emotion when interacting with an opposite-sex partner. This effect was also observed for ratings of emotional experience: male participants reported experiencing more happiness $\left(b_{11}=-.13, t=3.62, P<.001\right)$ and surprise $\left(b_{11}=-.12, t=2.99, P<.01\right)$, and marginally more sadness $\left(b_{11}=-.06, t=1.96, P<.05\right)$, nervousness $\left(b_{11}=-.06, t=1.98\right.$, $P<.05)$, and embarrassment $\left(b_{11}=-.04, t=2.20, P<.05\right)$, when interacting with a woman; female participants reported experiencing more of these emotions when interacting with men. The interaction between sex of participant and sex of partner was also significant for emotional intensity $\left(b_{11}=-.21, t=5.15, P<.001\right)$, indicating that participants reported experiencing more intense emotion when interacting with an opposite-sex partner.

Closeness of Other. Another set of HLM analyses, similar to those presented in equations 3 to 5 , were conducted to investigate whether men and women respond differentially to the closeness of their interaction partner. As in the previous analyses, we will focus on reporting $b_{11}$ and $b_{10}$ terms; $b_{01}$ terms will only be reported if they differ from the main effects for participants' sex already reported. Averaging across male and female participants, reports of happiness and sadness were positively associated with the closeness of the interaction partner (average $b_{10}=$ $0.10, t=5.78, P<.001$ ) and (average $b_{10}=.03, t=3.00, P<.01$ ); participants tended to report more happiness and sadness when interacting with close others as compared to strangers. Furthermore, on average, the intensity of participants' emotional experiences and their degree of emotional expression was positively associated with the closeness of the interaction partner (average $b_{10}=.11, t=6.73, P<.001$ ) and (average $\left.b_{10}=.16, t=8.76, P<.001\right)$, respectively.

Participants' sex, however, did not interact with the closeness of the interaction partner to produce differential emotional responses. The interaction terms $\left(b_{11}\right)$ were not significant in the analyses of any momentary emotion ratings, suggesting that men's and women's emotional responses 
were not differentially sensitive to the closeness of their interaction partner.

\section{Importance of the Social Context: Attributes of the Interaction}

Degree of Intimacy. We next considered whether men's and women's emotional responses to their social interactions differed depending on the degree of intimacy present in the interaction itself. As before, we used one HLM model to analyse each emotion rating. In many cases, participants' reports of emotion were positively associated with the degree of intimacy in the interaction. As the intimacy in the interaction increased, participants reported more happiness (average $b_{10}=.27, t=9.33, P<.001$ ), sadness (average $b_{10}=.12, t=5.06, P<.001$ ), surprise (average $b_{10}=.18, t=5.68$, $P<.001$ ), embarrassment (average $b_{10}=.04, t=2.38, P<.02$ ), and shame (average $b_{10}=.04, t=2.01, P<.02$ ). On average, both the intensity of emotion and expressions of emotion increased with increased intimacy (average $b_{10}=.42, t=15.87, P<.001$ ) and (average $b_{10}=.49, t=$ $15.85, P<.001)$, respectively.

Although reports of emotional experience and expression increased during intimate interactions, participants' sex did not interact with the intimacy of the interaction to produce differential emotional responses. Most of the $b_{11}$ coefficients did not reach significance. The only exception was for ratings of emotional expression (average $b_{11}=.08, t=2.37, P<.02$ ); the relationship between intimacy and increased emotional expression was stronger for women $\left(b_{1}=.57\right)$ than for men $\left(\left(b_{1}=.41\right)\right.$. Thus, women's emotional expressivity was more sensitive to the level of intimacy in their social interactions than was true for men. One finding for the $b_{10}$ term for emotional expression was interesting: After controlling for the level of intimacy in the interaction, men and women did not differ in the intensity of their emotional experience (average $b_{10}=.05, t=.91$, n.s.). Furthermore, on average, female participants rated their interactions as more intimate than did male participants [ $(M=3.21$ vs. $M=2.61), t=3.39, P<.001]$. Together, these findings suggest that sex differences in emotional intensity may be due, at least in part, to women construing their interactions as more intimate than do men.

Perceived Control. We next considered whether men's and women's emotional responses to their social interactions differed depending on the degree to which they felt in control of the interaction. Averaging across both male and female participants, reports of most specific emotions were not associated with the degree of perceived control in the interaction, with 
two exceptions. First, as the degree of personal control in the interaction increased, participants reported less surprise (average $b_{10}=.08, t=2.1$, $P<.04)^{6}$. Second, expressions of emotion increased with increases in personal control (average $b_{10}=-.12, t=3.1, P<.01$ ). No interaction term was statistically significant, indicating that degree of control in the interaction did not elicit sex differences in emotional experience or expression. Interestingly, on average, men displayed a trend to report more control over their interactions than did women [ $M=3.09$ vs. $M=2.97)$, $[t=2.14, P<.03]$. Women continued to report that they expressed more emotion than did men, however, even when degree of personal control in the interaction was held constant in the analysis.

\section{DISCUSSION}

Consistent with previous research, female participants in the present study described themselves as more affectively intense, open and sensitive to their feelings, anxious, sad, and happy than did men when responding to global, memory-based measures. This pattern was not observed, however, when these same men and women documented their emotional reactions on a moment-to-moment basis. Men and women did not differ in their average experience of specific emotions measured immediately after dyadic social interactions, although sex differences emerged on average in the global momentary ratings: Women consistently reported that they experienced more intense emotions and that they expressed their emotions more during those interactions. The appearance of sex differences in these more general momentary ratings, but not in those tapping the experience of specific emotions, is consistent with LaFrance and Banaji's (1992) view that sexrelated differences are more likely to occur when ratings are general rather than specific.

The remainder of the analyses in the present study were aimed at examining contexts that might enhance or attenuate sex-related differences in emotional experience and expression. We examined two types of context variables that we thought were particularly likely to elicit sexrelated emotion differences: Characteristics of the interaction partner (sex of interaction partner and closeness of interaction partner) and characteristics of the interaction (degree of intimacy and perceived personal control in the interaction). Many of these context variables were associated with ratings of momentary emotional experience and expression-indicating that they were emotionally evocative-but only sex of the interaction

\footnotetext{
${ }^{6}$ Perceived personal control was scaled so that low values for control indicate perceptions that the participant was in control of the interaction, whereas high values indicate perceptions that the interaction partner was in control of the interaction.
} 
partner seemed to elicit sex differences. Participants reported that they experienced and expressed more emotion when interacting with oppositesex partners. Given that the majority of our participants were probably heterosexual, many of these opposite-sex interactions may have had romantic content or overtones, increasing their emotional relevance and currency. The other partner-based attribute, closeness of the interaction partner, neither enhanced nor attenuated sex differences in emotional experience or expression.

As characteristics of the interactional context, intimacy and perceived personal control neither enhanced nor attenuated sex differences in emotional experience, despite the fact that women reported more intimacy in their interactions, whereas men reported more personal control in theirs. Not only did men and women differentially experience power and intimacy in their interactions, but they communicated this difference in some of their memory-based personality ratings: Women described themselves as warmer and more compliant than did men on the memory-based measures. This correspondence between memory-based descriptions and on-line ratings stands in contrast to the lower correspondence observed in the emotionality ratings. Even though men and women were differentially aware of intimacy and power aspects of their interactions, those interpersonal aspects failed to activate sex-related differences in emotional experience. Level of intimacy activated sex-related differences in emotional expression, however.

Taken together, the findings presented in this study present a challenge to the strongly held stereotype that women are "more emotional" than are men. At the very least, the data suggest that the answer to whether sex differences really exist depends primarily on how we ask the question and to some degree on the context in which the question is asked.

How can we account for the lack of correspondence between on-line and memory-based measures? One possible explanation is that the on-line ratings reflected reports of specific emotions, but the global, retrospective self-descriptions did not. An examination of the items on the personality questionnaires indicates that many of the items referred to specific emotional experiences (e.g. "I often feel tense and jittery", "I seldom feel sad or depressed", "I often get angry at the way people treat me", and "Sometimes I bubble with happiness".). Thus, it is possible that retrospective ratings of emotional characteristics elicit people's ideas about their general emotional response patterns for specific emotions, whereas the momentary ratings are based on specific emotions in specific situations.

It is also possible, however, that participants' descriptions of their own emotional characteristics may have been influenced by their beliefs about men's and women's emotionality more generally. To create such descriptions, participants had to recall information about past experiences and synthesise them into a consistent picture. The mere act of remembering is a 
reconstructive process aided by implicitly held theories (for reviews see Fiske \& Taylor, 1991; Greenwald \& Banaji, 1995; Nisbett \& Ross, 1989). Beliefs about sex differences in emotionality (Shields, 1991) may be rooted in social roles that specify that women are more emotionally responsive than men (Eagly, 1987; Wood, Rholes, \& Whelan, 1989). People may construct notions about their general emotional responsivity in line with the social role ascribed to their sex. As a result, role-guided responses may lead respondents to overestimate or underestimate the amount of emotion that they actually experienced during some previous time-span. In addition, sex-related differences in emotion may be more pronounced in laboratory settings than in real life settings (Eagly \& Wood, 1991) because laboratory settings eliminate other influences on an individual's emotional state (e.g. the immediate, context-driven norms of social situations). Participants completed their personality measures in a lab setting which may have caused them to fall back on their gender-based beliefs about emotionality.

An alternative explanation is that men and women may be differentially anchoring their response scales when making the different types of ratings. The typical response scale asks participants to respond to items by endorsing some number that reflects "not at all" to "very much" of some experience. Typically, when making such ratings, participants compare themselves to a target. When making global, retrospective self-descriptions of the type found on individual difference measures of emotionality, participants might compare themselves to the "average individual". When making ratings of their momentary emotional experiences, however, participants might anchor the response scale by comparing themselves to their own average emotional response. As a result, women might endorse the gender-linked belief that they are more emotional than the "average person", whereas men would endorse the complementary belief, when completing individual difference measures, but not when completing momentary measures.

A third possibility is that emotions may have differential value for men and women. Even though they may not differ in their momentary experiences, women may attend more to their emotions when they occur, think more about them, share their emotions more with other people, and find more meaning in their emotional reactions than men. These experiences may lead women to develop a more elaborated view of themselves as an emotional being than typically occurs for men. In addition, perhaps interaction partners expect women to emit more emotion than men (Keltner, 1995), leading those partners to respond more frequently to women's displays of emotion. This responsivity may cause women to perceive their emotional displays as intense enough to elicit strong responses from others, leading women to develop a perception of their own emotional experiences and expression as more intense than do men. 


\section{Limitations of the Study}

Our inability to detect strong context effects for sex differences in emotional experience and expression may be directly related to certain limitations of our study. It might be argued that we failed to detect the influence of the social context variables because of the ways in which we operationalised them. Rather than asking participants how important each goal (i.e. intimacy or power) was to them, we asked them to make a judgement about the content of that goal (i.e. how much intimacy or power was relevant to the situation). The present study documented that, on a moment-to-moment basis, women perceived their interactions as more intimate than did men, whereas men perceived their interactions as involving more personal control. Although these sex-related differences are consistent with the notion that men and women hold different interpersonal goals, we did not directly assess the degree to which individuals held intimacy or power goals. For example, participants were asked "who was in control of this interaction: $1=$ you to 5 $=$ your interaction partner? Perceived personal control could be relatively high in a particular interaction, even if the participant did not desire personal control; in such a case, the influence of this context variable might be diminished. Future research should focus directly on the goals that men and women have for their social interactions, as well as on how emotional experience and expression are linked to achieving interpersonal goals.

In addition, using a general item for emotional expression may have limited the results of the study. Measuring expression of specific emotions, rather than emotional expression in general, would shed more light on the sex-linked difference that we noted. In particular, if differences disappear when specific emotional expressions are measured, then the difference in the current study could be attributed to the generality of the question. On the other hand, if sex-linked differences in expression remain, that would be consistent with the notion that differences in emotional expression are due to differential socialisation and prescribed gender roles. Asking questions about expression of specific emotions would also allow us to address whether particular emotions (e.g. anger) might be expressed more by men than by women, because of their gender roles.

Furthermore, it would be productive to assess the degree of congruence between an experienced emotion and the form of its subsequent expression. Although the experience of a particular emotion is often displayed in a fashion consistent with that emotion (e.g. a smile when one is happy), it is possible for an individual to experience one emotion but display it as a different, more socially appropriate emotion (e.g. felt embarrassment is displayed as anger). Sex-related differences may be more properly found in the nature of the congruence between experience and expression, rather than the degree of correspondence, per se. We did conduct analyses to 
examine the amount of experience-expression congruence, we found no sex differences on average or in particular social contexts; our analyses were limited, however, by the fact that we were comparing specific emotional experiences to a global rating of expression.

Finally, participants in this study were originally selected for a study of adult attachment styles. As a result, our sample consisted of roughly equal numbers of individuals with four attachment styles; about one quarter of our sample was securely attached, whereas three-quarters of our sample was insecurely attached. Despite the potential for a confound, it is unlikely that the present findings were biased by our sampling procedure. Some insecurely attached individuals (e.g. fearful ambivalents and preoccupieds) are thought to experience heightened emotional responses when compared to securely attached individuals, whereas others (dismissive avoidants) are thought to experience reduced emotional responses (Bartholomew \& Horowitz, 1991). In addition, the findings from this study directly replicate findings from two studies (Feldman Barrett \& Morganstein, 1996) using samples that were not selected on the basis of any personality variable.

\section{Implications}

These findings have several major implications. First, sex differences in emotional experience are not as pervasive as the stereotype suggests. Men and women do not differ dramatically in their immediate reports of emotional experience, even in contexts that are differentially relevant for men and women (control vs. intimacy). This finding raises the possibility that women's "greater emotionality" is a culturally constructed idea, based on observed differences in emotional expression-differences which are socialised from a very early age. Second, investigators should be wary of including only global, retrospective self-descriptions of emotional experience when conducting research on affective experience. Self-report ratings of this type, although informative, may provide a skewed picture of the emotional life of a person-a picture skewed in the direction of supporting gender-based stereotypes about emotion.

Manuscript received 16 December 1996 Revised manuscript received 7 October 1997

\section{REFERENCES}

Aiken, L.S., \& West, S.G. (1991). Multiple regression: Testing and interpreting interactions. Newbury Park, CA: Sage.

Allen, J.G., \& Haccoun, D.M. (1976). Sex differences in emotionality: A multidimensional approach. Human Relations, 29, 711-722. 
Bartholomew, K., \& Horowitz, L.M. (1991). Attachment styles among young adults: A test of a four-category model. Journal of Personality and Social Psychology, 61, 226-244.

Birnbaum, D.W., \& Croll, W.L. (1984). The etiology of children's stereotypes about sex differences in emotionality. Sex Roles, 10, 677-691.

Birnbaum, D.W., Nosanchuk, T.A., \& Croll, W.L. (1980). Children's stereotypes about sex differences in emotionality. Sex Roles, 6, 435-443.

Brody, L.R., \& Hall, J.A. (1993). Gender and emotion. In M. Lewis and J. Haviland (Eds.), Handbook of emotions (pp. 447-460). New York: Guilford Press.

Bryk, A.S., \& Raudenbush, S.W. (1987). Application of hierarchical linear models to assessing change. Psychological Bulletin, 101, 147-158.

Bryk, A.S., \& Raudenbush, S.W. (1992). Hierarchical linear models: Applications and data analysis methods. Newbury Park, CA: Sage.

Bryk, A.S., Raudenbush, S.W., Seltzer, M., \& Congdon, R.T. (1989). An introduction to HLM: Computer program and user's guide. Chicago, IL: University of Chicago.

Chodorow, N. (1978). The reproduction of mothering. Berkeley, CA: UCLA Press.

Costa, P.T., \& McCrae, R.R. (1992). The Revised NEO Personality Inventory (NEO PI-R) professional manual. Odessa, FL: Psychological Assessment Resources.

Deaux, K., \& Major, B. (1987). Putting gender into context: An interactive model of gender-related behavior. Psychological Review, 94, 369-389.

Diener, E., Sandvik, E., \& Larsen, R.J. (1985). Age and sex effects for emotional intensity. Developmental Psychology, 21, 542-546.

Dindia, K., \& Allen, M. (1992). Sex differences in self-disclosure: A meta-analysis. Psychological Bulletin, 112. 106-124.

Dosser, D.A., Balswick, J.O., \& Halverson, C.F. (1983). Situational content of emotional expressions. Journal of Counseling Psychology, 30, 375-387.

Eagly, A.H. (1987). Sex differences in social behavior: A social-role interpretation. Hillsdale, NJ: Erlbaum.

Eagly, A.H., \& Wood, W. (1991). Explaining sex differences in social behavior: A metaanalytic perspective. Personality and Social Psychology Bulletin, 17, 306-315.

Fabes, R.A., \& Martin, C.J. (1991). Gender and age stereotypes in emotionality. Personality and Social Psychology Bulletin, 17, 532-540.

Feldman Barrett, L., \& Morganstein, M. (1996). Sex differences in the experience of emotion: Retrospective versus momentary ratings. Unpublished manuscript, Boston College.

Feldman Barrett, L., \& Pietromonaco, P.R. (1997). Accuracy of the five factor model in predicting perceptions of daily social interactions. Personality and Social Psychology Bulletin, 23, 1173-1187.

Fischer, A. (1993). Sex difference in emotionality: Fact or stereotype? Feminism and Psychology, 3, 303-318.

Fiske, S.T., \& Taylor, S.E. (1991). Social cognition (2nd ed.). New York: McGraw-Hill.

Fujita, F., Diener, E., \& Sandvik, E. (1991). Gender differences in negative affect and wellbeing: The case for emotional intensity. Journal of Personality and Social Psychology, $61,427-434$.

Greenwald, A.G., \& Banaji, M.R. (1995). Implicit social cognition: Attitudes, self-esteem, and stereotypes. Psychological Review, 102, 4-27.

Grossman, M., \& Wood, W. (1993). Sex differences in intensity of emotional experience: A social role interpretation. Journal of Personality and Social Psychology, 65, 1010-1022.

Hochschild, A.R. (1983). The managed heart: Commercialization of human feeling. Berkeley, CA: University of California Press. 
Josephs, R.A., Markus, H., \& Tafarodi, R.W. (1992). Gender and self-esteem. Journal of Personality and Social Psychology, 63, 391-402.

Keltner, D. (1995). Signs of appeasement: Evidence for the distinct displays of embarrassment, amusement, and shame. Journal of Personality and Social Psychology, 68, 441-454.

Kenny, D.A., Kashy, D.A., \& Bolger, N. (1998). Data analysis in social psychology. In D. Gilbert, S.T. Fiske, \& G. Lindzey (Eds.), Handbook of social psychology (4th ed., Vol. 1, pp. 233-265). New York: McGraw-Hill.

Kring, A.M., Smith, D.A., \& Neale, J.M. (1994). Individual differences in dispositional expressiveness: Development and validation of the Expressiveness Scale. Journal of Personality and Social Psychology, 66, 934-949.

LaFrance, M., \& Banaji, M. (1992). Towards a reconsideration of the gender-emotion relationship. In M.S. Clark (Ed.), Emotion and social behavior: Review of personality and social psychology (Vol. 14, pp. 178-201). Newbury Park, CA: Sage.

Larsen, R., \& Diener, E. (1987). Affect intensity as an individual difference characteristic. Journal of Research in Personality, 21, 1-39.

Lutz, C.A. (1990). Engendered emotion: Gender, power, and the rhetoric of emotional control in American discourse. In C. Lutz \& L. Abu-Lughod (Eds.), Language and the politics of emotion (pp. 69-91). Cambridge, UK: Cambridge University Press.

Maccoby, E.E. (1990). Gender and relationships: A development account. American Psychologist, 45, 513-520.

Markus, H., \& Oyserman, D. (1989). Gender and thought: The role of the self-concept. In M. Crawford \& M. Hamilton (Eds.), Gender and thought (pp. 7-22). New York: Wiley.

Miller, J.B. (1984). The development of women's sense of self. Working paper No. 12. Wellesley, MA: Stone Center Working Paper Series.

Nisbett, R.E., \& Ross, L. (1980). Human inference: Strategies and shortcomings of social judgment. Englewood Cliffs, NJ: Prentice-Hall.

Pietromonaco, P.R., \& Feldman Barrett, L. (1997). Working models of attachment daily social interactions. Journal of Personality and Social Psychology, 73, 1409-1423.

Reis, H.T., \& Wheeler, L. (1991). Studying social interaction with the Rochester Interaction Record. In M.P. Zanna (Ed), Advances in experimental social psychology (Vol. 24, pp. 269-318). San Diego, CA: Academic Press.

Ross, M. (1989). Relation of implicit theories to the construction of personal histories. Psychological Review, 96, 341-357.

Schwarz, N., \& Sudman, S. (1994). Autobiographical memory and the validity of retrospective reports. New York: Springer.

Sherrod, D. (1989). The influence of gender on same-sex friendships. In C. Hendrick (Ed.), Close relationships: Review of personality and social psychology (pp. 164-186). Newbury Park, CA: Sage.

Shields, S.A. (1987). Women, men and the dilemma of emotions. In P. Shaver, \& C. Hendrick (Eds.), Sex and gender: Review of personality and social psychology (pp. 229-240). Newbury Park, CA: Sage.

Shields, S.A. (1991). Gender in the psychology of emotion: A selective research review. In K.I. Strongman (Ed.), International review of studies on emotion (Vol. 1, pp. 227-245). New York: Wiley.

Snell, W.E., Miller, R.S., \& Belk, S.S. (1988). Development of the Emotional SelfDisclosure Scale. Sex Roles, 18, 467-485.

Snell, W.E., Miller, R.S., Belk, S.S., Garcia-Falconi, R., \& Hernandez-Sanchez, J.E. (1989). Men's and women's emotional disclosures: The impact of disclosure recipient, culture, and the masculine role. Sex Roles, 21, 467-485. 


\section{FELDMAN BARRETT ET AL.}

Sprecher, S., \& Sedikides, C. (1993). Gender differences in perceptions of emotionality: The case of close heterosexual relationships. Sex Roles, 28, 511-530.

Stone, A.A., \& Shiffman, S. (1994). Ecological momentary assessment (EMA) in behavioral medicine. Annals of Behavioral Medicine, 16, 199-202.

Wood, W., Rholes, N., \& Whelan, M. (1989). Sex differences in positive well-being: A consideration of emotional style and mental status. Psychological Bulletin, 106, $249-264$. 